\title{
Effects of Short-term Mobile Application Use on Weight Reduction for Patients with Type 2 Diabetes
}

\author{
Seung Eun Lee', Su-Kyung Park², Ye-Seul Park², Kyoung-Ah Kim', Han Seok Choi', Sang Woo Oh ${ }^{2, *}$ \\ Departments of ${ }^{1}$ Internal Medicine and ${ }^{2}$ Family Medicine, Dongguk University Ilsan Hospital, Dongguk University College of Medicine, Goyang, Korea
}

Background: The increasing prevalence of type 2 diabetes mellitus (T2DM) has led to a significant health burden. Technological advancements have highlighted the benefits of digital therapeutics for chronic diseases. In this study, we aimed to investigate the effects of a mobile application on weight reduction in patients with T2DM.

Methods: A total of 48 patients with T2DM was included in this single-center, randomized, controlled trial. In addition to conventional treatment, participants in the intervention group used a mobile application-based selfmanagement system for diet, exercise, and medication adherence. The primary outcome of this study was weight change after 3 months of intervention, and secondary outcomes were metabolic parameters.

Results: After 12 weeks, no significant differences in body weight change were observed between the intervention and control groups $(P=0.229)$. However, a significant difference was found in waist circumference (WC) between the two groups, wherein the control group showed an increase in WC (from $95.00 \pm 8.89 \mathrm{~cm}$ to $95.76 \pm$ $9.72 \mathrm{~cm}$ ), while the intervention group showed a reduction (from $91.93 \pm 6.25 \mathrm{~cm}$ to $90.75 \pm 6.01 \mathrm{~cm}$ ) with a significant time by group interaction $(P=0.016)$. Additionally, participants with good compliance exhibited a more evident reduction in WC $(P=0.037)$. However, no significant differences were found in other metabolic parameters between the two groups.

Conclusion: Lifestyle modification using short-term mobile applications effectively reduced WC, especially in patients with good adherence to the application. However, weight reduction was not achieved.

Key words: Diabetes mellitus type 2, Waist circumference, Body weight changes, Mobile applications
Received April 13, 2021

Reviewed July 11, 2021

Accepted August 11, 2021

*Corresponding author

Sang Woo Oh

(iD)

https://orcid.org/0000-0002-5623-6720

Department of Family Medicine, Dongguk University Ilsan Hospital, 27 Dongguk-ro, llsandong-gu, Goyang 10326, Korea Tel: $+82-31-961-5770$ Fax: +82-31-961-5944 E-mail: osw6021@naver.com

\section{INTRODUCTION}

The increase in type 2 diabetes mellitus (T2DM) prevalence has affected > 460 million people worldwide. ${ }^{1}$ The International Diabetes Federation Diabetes Atlas predicted a continued increase in T2DM prevalence, reaching approximately 700 million by 2045 . $^{2}$ A 60\% increase in mortality rate is observed in patients with T2DM compared to healthy individuals. ${ }^{3}$ In addition to its high mortality rate, diabetes is associated with an increased risk for a myriad of complications. ${ }^{4}$ During the past decades, advances in the management of T2DM have been achieved, leading to the availability of newer classes of antidiabetic drugs exhibiting fewer side effects and more favorable mechanisms. ${ }^{5}$ Nevertheless, the increase in T2DM prevalence has led to a concomitant increase in vascular complications and increased mortality. ${ }^{6}$

Intensive lifestyle modification is known to effectively prevent T2DM when combined with $\geq 7 \%$ weight reduction. ${ }^{7}$ Early application of lifestyle interventions in T2DM appears to be particularly beneficial before loss of beta cell function and mass. ${ }^{8}$ However, implementation and maintenance of a healthy lifestyle present a significant challenge to patients with T2DM. A long-term follow-up study of a randomized clinical trial demonstrated body weight re-

Copyright (C) 2021 Korean Society for the Study of Obesity

(a) This is an Open Access article distributed under the terms of the Creative Commons Attribution Non-Commercial License (https://creativecommons.org/licenses/by-nc/4.o/) which permits unrestricted non-commercial use, distribution, and reproduction in any medium, provided the original work is properly cited 
gain among participants in the lifestyle intervention group after completion of the original study. ${ }^{9}$

Digital therapeutics have been proposed for management of medical conditions through patient behavior modification. ${ }^{10}$ Compared to clinical pharmacology, digital therapeutics are tailored to chronic diseases wherein behavioral modification is essential. ${ }^{11}$ The management of chronic diseases in the hospital setting alone is inefficient as most chronic diseases develop outside healthcare settings; therefore, effective outpatient programs using digital health therapeutics are necessary. ${ }^{11}$

Previous studies have investigated the effectiveness of mobile applications on weight loss. As expected, the greater was participant engagement in the application, the higher was the achieved treatment effect. ${ }^{12}$ Unfortunately, use of the application decreased substantially 1 month after treatment initiation. ${ }^{12}$ Thus, it is important to maintain long-term user engagement. Contrary to a previous observation where a mobile application was beneficial only when combined with behavioral counseling, ${ }^{13}$ a recent study showed that a mobile application with self-monitoring can be effective and has a high engagement rate. ${ }^{12}$ In this study, we aimed to evaluate the effectiveness of mobile applications without in-person intervention in the weight management of patients with T2DM and their implications on metabolic parameters.

\section{METHODS}

\section{Study design and population}

This study was a single-center, prospective, randomized clinical trial of an exploratory nature. Participants were recruited from the endocrinology outpatient clinic of Dongguk University Ilsan Hospital, located in an urban city in South Korea. We included T2DM patients with glycosylated hemoglobin (HbAlc) level $\geq 6.5 \%$ who were being treated with antidiabetic medications. Exclusion criteria were (1) severe comorbidities preventing regular diet, exercise, or sleep (e.g., gastrointestinal motility disorder, severe chronic obstructive pulmonary disease), (2) recent history of myocardial infarction or stroke (within the preceding 6 months), and (3) history of dementia or drug/alcohol substance abuse.

A total of 50 participants was enrolled and randomly allocated into two groups: the control group $(n=25)$, in which patients re- ceived conventional treatment consisting of an educational program for diet, exercise, and medication adherence presented by a clinical research nurse at their first visit, and the intervention group $(n=25)$, in which patients received the same conventional treatment plus use of a mobile application managing diet, exercise, and medication adherence. Assessments were performed at baseline and at 3 months between September 2019 and February 2020. The Institutional Review Board of Dongguk University Ilsan Hospital approved this study (IRB No. DUIH 2019-02-022-007), and all participants provided written informed consent.

\section{Mobile application}

Participants in the intervention group received lifestyle management assistance using mobile applications. The LIBIT application (Huraypositive, Seoul, Korea) was used for dietary and exercise management, while the Medilarm application (GST Korea, Seoul, Korea) was used to improve medication adherence. The representative user interfaces on a patient's mobile application are presented in Supplementary Fig. 1.

\section{LIBIT application}

The LIBIT application calculated the calories participants needed based on their height and weight (ideal body weight $[\mathrm{IBW}] \times 25$, if the actual body weight $[\mathrm{ABW}]$ of the participant was $\geq 120 \%$ of the IBW, or IBW $\times 30$ for an ABW < 120\%). ${ }^{14}$ Participants were instructed to either directly enter calories consumed into the application or select foods from the nutrient database, which contains 9,259 food types. When selecting food types from the database, a voice recognition system was used to improve compliance. The LIBIT application then evaluated diet appropriateness, provided a graph showing nutrient intake, and sent feedback messages to encourage healthy dietary patterns.

The exercise management service included 21 types of easy exercises. The participants were instructed to input the type, duration, and intensity of exercise. Consumed calories were calculated automatically based on the metabolic equivalent task (MET) $)^{15}$ using the following equation: calorie consumption $=($ MET $\times$ duration of exercise $[\mathrm{min}] \times$ body weight $[\mathrm{kg}] \times 0.0035) \times 5$. 


\section{Medilarm application}

The patients input information regarding prescribed medications into the Medilarm application, which then sent reminders to take their medications at the appropriate time. If participants failed to record the dose taken, three additional messages were sent, one every 20 minutes, to encourage medication adherence.

We divided the patients into good compliance and poor compliance groups according to data input. According to a previous study ${ }^{16}$ that reported up to $70 \%$ medication adherence to antidiabetic medications, we defined patients as having good drug adherence if they recorded $\geq 2 / 3$ of their drug intake. Input frequencies of diet and exercise were much lower than those of medication adherence; the mean input was up to $50 \%$ and up to $10 \%$ for diet and exercise, respectively. Thus, we defined cutoff values of good compliance for diet and exercise as $\geq 1 / 2$ nutritional information input and exercise at least once a week, respectively. Collectively, if patients recorded $\geq 2 / 3$ drug administration, $\geq 1 / 2$ nutritional information, and exercise at least once a week, they were included in the good compliance group. Otherwise, the participants were included in the poor compliance group.

\section{Follow-up and outcomes}

Prior to and 3 months after participation, height, body weight, and waist circumference (WC) were measured. Additionally, blood samples were collected to examine the levels of fasting blood sugar (FBS), HbAlc, total cholesterol, triglyceride, low-density lipoprotein (LDL) cholesterol, and high-density lipoprotein (HDL) cholesterol. Body mass index (BMI) was calculated as weight divided by height squared $\left(\mathrm{kg} / \mathrm{m}^{2}\right)$. WC was measured by a trained nurse at the midpoint between the lower margin of the last palpable rib and the top of the iliac crest, as recommended by the World Health Organization. ${ }^{17}$ To minimize measurement errors, the same examiner performed WC measurement of the same participants at visits 1 and 2 . Venous blood was drawn after 12 hours of fasting, and all biochemical tests were performed using an automatic analyzer (Cobas 6500 model; Roche, Basel, Switzerland) within the Department of Laboratory Medicine at Dongguk University Ilsan Hospital.

The primary outcome of this study was weight change after 3 months of intervention compared to the control. Secondary outcomes were associated metabolic parameters of WC, FBS, $\mathrm{HbAlc}$, lipid profile, blood pressure (BP), and continuous values of metabolic syndrome risk scores (cMetS). ${ }^{18}$

cMetS is a standardized metabolic syndrome score that indicates the severity of metabolic abnormalities as a continuous value. cMetS was computed as the sum of standardized residuals (Z-score) of metabolic indicators, including mean arterial pressure (MAP), triglycerides, FBS, WC, and HDL cholesterol multiplied by -1 according to a previous study. ${ }^{18}$ The 8th Korea National Health and Nutrition Examination Survey (2019) database was used as the reference population. MAP was calculated as follows: $\mathrm{MAP}=$ diastolic BP+(1/3) (systolic BP-diastolic BP). The HDL cholesterol value is associated inversely with metabolic risk and was multiplied by -1 prior to being incorporated into the cMetS.

\section{Comorbidities}

Participants were defined as having hypertension or dyslipidemia if they had a relevant diagnosis in their electronic medical records or if their responses to the questionnaire reflected hypertension or dyslipidemia. In addition, hypertension was defined as a systolic BP $\geq 140 \mathrm{mmHg}$ and/or diastolic BP $\geq 90 \mathrm{mmHg}$. On the other hand, dyslipidemia was defined as a total cholesterol level $\geq 240 \mathrm{mg} / \mathrm{dL}$.

Metabolic syndrome was defined using the revised National Cholesterol Education Program, with an Asian-specific WC threshold. ${ }^{19,20}$ Briefly, participants were defined as having metabolic syndrome if they met $\geq 3$ of the following criteria: (1) abdominal obesity: WC $\geq 90 \mathrm{~cm}$ in men or $\geq 80 \mathrm{~cm}$ in women, (2) hypertriglyceridemia: triglycerides $\geq 150 \mathrm{mg} / \mathrm{dL}$, (3) low HDL cholesterol: HDL cholesterol $<40 \mathrm{mg} / \mathrm{dL}$ in men and $<50 \mathrm{mg} / \mathrm{dL}$ in women, (4) high BP: systolic $\mathrm{BP} \geq 130 \mathrm{mmHg}$ and/or diastolic $\mathrm{BP} \geq 85 \mathrm{mmHg}$ or use of antihypertensive agents, and (5) hyperglycemia: FBS $\geq 100 \mathrm{mg} / \mathrm{dL}$ or use of antidiabetic medication.

\section{Statistical analysis}

Descriptive statistics were used to summarize baseline characteristics. To compare them, an independent t-test for continuous variables and a chi-square test for categorical variables were used. Primary and secondary outcomes were analyzed using repeated-measures analysis of variance (ANOVA) with age as the covariate. Repeated-measures ANOVA was conducted omitting subjects which have missing values. The within-subjects effect between time points 
was denoted as "time." A significant $P$-value for "time" is defined by overall significant outcome changes through the study period. On the other hand, a significant "time $\times$ group interaction" indicates a significantly different response throughout the study period between the two groups. All statistical analyses were performed using SPSS version 18.0 (SPSS Inc., Chicago, IL, USA), and $P<0.05$ was considered to be statistically significant.

\section{RESULTS}

The participants' baseline characteristics are shown in Table 1. During the study period, two patients in the intervention group were excluded due to loss to follow-up and consent withdrawal, yielding a final sample size of 48 . The participants had a mean age of 59.6 years (standard deviation [SD], 9.0 years) and a mean BMI of $26.3 \mathrm{~kg} / \mathrm{m}^{2}$ (SD, $3.3 \mathrm{~kg} / \mathrm{m}^{2}$ ). Among the participants, $58.3 \%$, 79.2\%, and 93.8\% had hypertension, dyslipidemia, and metabolic syndrome, respectively. Patients in the intervention group were younger $(56.0 \pm 8.1$ years vs. $63.0 \pm 8.5$ years, $P=0.01)$ and less likely to have hypertension $(39.1 \%$ vs. $76 \%, P=0.02)$ or diabetic nephropathy ( $8.7 \%$ vs. $44.0 \%, P=0.02$ ) than the control group. Other demographic profiles, including BMI, diabetes duration, and sex, did not differ between groups.

During the study period, no major modifications in the initially prescribed medications for diabetes, hypertension, or dyslipidemia were performed, except in one patient in the intervention group who underwent beta-blocker dose escalation. The patients in the two groups experienced similar changes in mean body weight (from
$68.3 \mathrm{~kg}$ to $69.7 \mathrm{~kg}$ in the control group and from $71.4 \mathrm{~kg}$ to $72.0 \mathrm{~kg}$ in the intervention group), with no group difference $(P=0.229)$ (Fig. 1A). We investigated whether certain parameters had a significant correlation with body weight changes. Positive correlations were found between body weight change and baseline levels of triglycerides $(r=0.329)$, LDL cholesterol $(r=0.329)$, and total cho-

Table 1. Baseline characteristics of the study population

\begin{tabular}{lccc}
\hline Variable & $\begin{array}{c}\text { Control group } \\
(\mathrm{n}=25)\end{array}$ & $\begin{array}{c}\text { Intervention group } \\
(\mathrm{n}=23)\end{array}$ & $P$ \\
\hline Age $(\mathrm{yr})$ & $63.0 \pm 8.5$ & $56.0 \pm 8.1$ & $0.005^{*}$ \\
Women & $14(56.0)$ & $13(56.5)$ & 1.000 \\
Height $(\mathrm{cm})$ & $160.3 \pm 9.4$ & $165.2 \pm 8.0$ & 0.060 \\
Body weight (kg) & $68.3 \pm 12.4$ & $71.5 \pm 12.1$ & 0.374 \\
Waist circumference (cm) & $95.0 \pm 8.9$ & $91.9 \pm 6.3$ & 0.184 \\
BMI (kg/m²) & $26.5 \pm 3.5$ & $26.1 \pm 3.1$ & 0.654 \\
Duration of diabetes (yr) & $10.8 \pm 8.0$ & $7.9 \pm 6.3$ & 0.164 \\
Diabetic retinopathy & $9(36.0)$ & $5(21.7)$ & 0.311 \\
Diabetic nephropathy & $11(44.0)$ & $2(8.7)$ & $0.015^{*}$ \\
HbA1c (\%) & $7.6 \pm 0.8$ & $7.4 \pm 0.6$ & 0.401 \\
FBS (mg/dL) & $136.9 \pm 39.0$ & $137.5 \pm 22.5$ & 0.944 \\
Antidiabetic drug & & & \\
SGLT-2i & $8(32.0)$ & $8(34.8)$ & 1.000 \\
TZD & $4(16.0)$ & $5(21.7)$ & 0.890 \\
Insulin & $6(24.0)$ & $3(13.0)$ & 0.548 \\
Comorbidity & & & \\
Hypertension & $19(76.0)$ & $9(39.1)$ & $0.022^{*}$ \\
Dyslipidemia & $20(80.0)$ & $18(78.3)$ & 1.000 \\
Metabolic syndrome & $24(96.0)$ & $21(91.3)$ & 0.721 \\
\hline
\end{tabular}

Values are presented as mean \pm standard deviation or number $(\%)$.

${ }^{*}$ Statistical significance at the $P<0.05$ level. An independent t-test for continuous variables and a chi-square test for categorical variables were used.

$\mathrm{BMI}$, body mass index; HbA1c, glycosylated hemoglobin; FBS, fasting blood sugar; SGLT-2i, sodium-glucose co-transporter 2 inhibitor; TZD, thiazolidinediones.
A

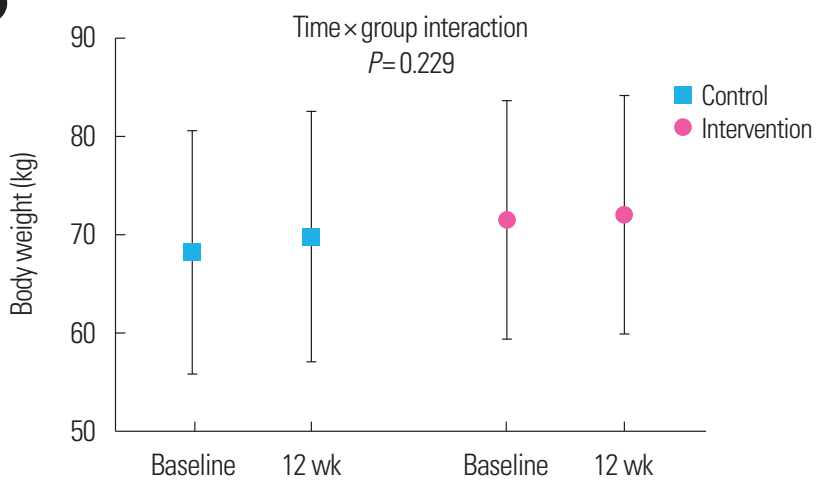

B

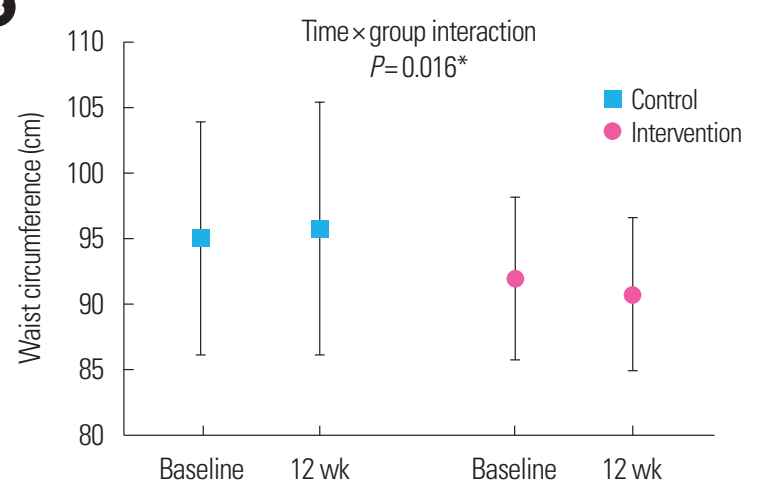

Figure 1. Changes in body weight (A) and waist circumference (B) from baseline to week 12 . The changes in body weight and waist circumference during the 12 weeks were analyzed by repeated-measures analysis of variance with age as the covariate. $P$-values indicate the time $\times$ group interaction. * Statistically significant difference. 
lesterol $(r=0.366)$. A negative correlation between body weight change and age was observed $(\mathrm{r}=-0.384)$. However, no correlation was statistically significant (Table 2 ). With respect to WC changes, the control group showed an increase in WC (from 95.00 \pm 8.89 $\mathrm{cm}$ to $95.76 \pm 9.72 \mathrm{~cm}$ ), while the intervention group showed a reduction (from $91.93 \pm 6.25 \mathrm{~cm}$ to $90.75 \pm 6.01 \mathrm{~cm}$ ) with a significant time $\times$ group interaction $(P=0.016)$ (Fig. 1B).

Table 3 describes the changes in mean secondary outcomes. No significant time $\times$ group interactions were observed for any second-

Table 2. Pearson's correlation analyses and identification of covariates significantly associated with body weight change

\begin{tabular}{lcc}
\hline Variable & Correlation coefficient & $P$ \\
\hline Age $(\mathrm{yr})$ & -0.384 & 0.078 \\
Body weight $(\mathrm{kg})$ & -0.147 & 0.512 \\
FBS $(\mathrm{mg} / \mathrm{dL})$ & 0.149 & 0.509 \\
Triglyceride $(\mathrm{mg} / \mathrm{dL})$ & 0.329 & 0.146 \\
$\mathrm{HDL}$ cholesterol $(\mathrm{mg} / \mathrm{dL})$ & -0.090 & 0.699 \\
LDL cholesterol $(\mathrm{mg} / \mathrm{dL})$ & 0.329 & 0.145 \\
Total cholesterol (mg/dL) & 0.366 & 0.103 \\
SBP $(\mathrm{mmHg})$ & -0.131 & 0.571 \\
DBP $(\mathrm{mmHg})$ & -0.269 & 0.238 \\
Duration of diabetes $(\mathrm{yr})$ & -0.103 & 0.647 \\
BMl $\left(\mathrm{kg} / \mathrm{m}^{2}\right)$ & -0.177 & 0.431
\end{tabular}

FBS, fasting blood sugar; HDL, high-density lipoprotein; LDL, low-density lipoprotein; SBP, systolic blood pressure; DBP, diastolic blood pressure; BMl, body mass index. ary outcomes except WC. As the proportion of patients with hypertension at baseline differed significantly, we additionally performed repeated-measures ANOVA analyses with age and hypertension as covariates. The results were consistent regardless of adjustment for hypertension (data not shown).

We examined the influence of application compliance on changes in WC. The mean changes in WC were $-3.0 \mathrm{~cm},-0.7 \mathrm{~cm}$, and $0.8 \mathrm{~cm}$ among those with good compliance, poor compliance, and without the application, respectively $(P=0.037)$ (Fig. 2). Conversely,

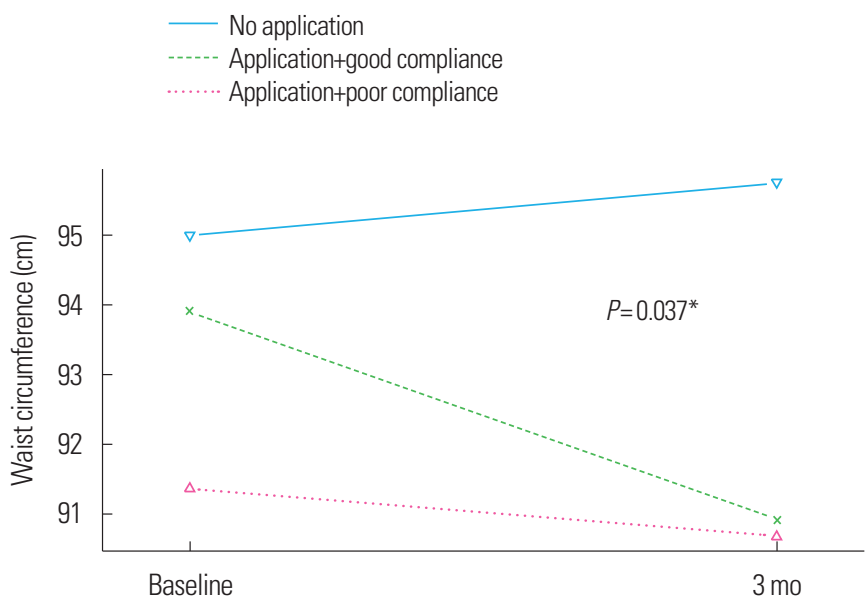

Figure 2. Impact of compliance with mobile application on mean waist circumference change. *Statistical significance at the $P<0.05$ level.

Table 3. Results of repeated-measures ANOVA testing with age as the covariate for changes in metabolic parameters from baseline to week 12

\begin{tabular}{|c|c|c|c|c|c|c|}
\hline \multirow{2}{*}{ Variable } & \multicolumn{2}{|c|}{ Control } & \multicolumn{2}{|c|}{ Intervention } & \multicolumn{2}{|c|}{$P$} \\
\hline & Baseline & $12 \mathrm{wk}$ & Baseline & $12 \mathrm{wk}$ & Time & Time $\times$ group \\
\hline Body weight (kg) & $68.3 \pm 12.4$ & $69.7 \pm 12.8$ & $71.4 \pm 12.4$ & $72.0 \pm 12.3$ & 0.452 & 0.229 \\
\hline $\mathrm{BMI}\left(\mathrm{kg} / \mathrm{m}^{2}\right)$ & $26.5 \pm 3.6$ & $27.1 \pm 3.6$ & $26.0 \pm 3.2$ & $26.3 \pm 3.1$ & 0.707 & 0.239 \\
\hline Waist circumference $(\mathrm{cm})$ & $95.0 \pm 8.9$ & $95.8 \pm 9.7$ & $91.9 \pm 6.3$ & $90.8 \pm 6.0$ & 0.231 & $0.016^{*}$ \\
\hline $\mathrm{FBS}(\mathrm{mg} / \mathrm{dL})$ & $136.9 \pm 39.0$ & $142.2 \pm 36.1$ & $137.5 \pm 22.5$ & $138.4 \pm 27.8$ & 0.635 & 0.895 \\
\hline $\operatorname{HbA1c}(\%)$ & $7.6 \pm 0.8$ & $7.7 \pm 1.0$ & $7.4 \pm 0.6$ & $7.7 \pm 0.8$ & 0.797 & 0.273 \\
\hline Triglyceride (mg/dL) & $147.4 \pm 62.1$ & $175.4 \pm 108.2$ & $163.7 \pm 128.8$ & $156.0 \pm 95.3$ & 0.549 & 0.271 \\
\hline HDL cholesterol (mg/dL) & $49.3 \pm 12.2$ & $50.5 \pm 16.5$ & $47.3 \pm 9.4$ & $49.2 \pm 7.6$ & 0.092 & 0.742 \\
\hline LDL cholesterol (mg/dL) & $88.4 \pm 39.8$ & $76.6 \pm 27.2$ & $72.6 \pm 25.7$ & $77.7 \pm 27.6$ & 0.487 & 0.058 \\
\hline Total cholesterol (mg/dL) & $157.3 \pm 46.1$ & $149.6 \pm 40.0$ & $139.5 \pm 39.8$ & $140.6 \pm 36.8$ & 0.655 & 0.362 \\
\hline $\mathrm{SBP}(\mathrm{mmHg})$ & $135.2 \pm 14.2$ & $138.7 \pm 13.9$ & $127.2 \pm 13.5$ & $133.9 \pm 15.9$ & 0.569 & 0.691 \\
\hline $\mathrm{DBP}(\mathrm{mmHg})$ & $77.6 \pm 8.1$ & $79.4 \pm 9.1$ & $78.6 \pm 7.3$ & $80.6 \pm 7.7$ & 0.439 & 0.778 \\
\hline cMetS & $3.7 \pm 2.9$ & $3.3 \pm 3.7$ & $3.5 \pm 2.8$ & $3.6 \pm 2.6$ & 0.882 & 0.647 \\
\hline
\end{tabular}

Values are presented as mean \pm standard deviation.

*Statistical significance at $P<0.05$. $P$-values were analyzed using repeated-measures ANOVA with age as the covariate. Columns represent the effects of time, group, and time $\times$ group interactions.

ANOVA, analysis of variance; BMI, body mass index; FBS, fasting blood sugar; HbA1c, glycosylated hemoglobin; HDL, high-density lipoprotein; LDL, low-density lipoprotein; SBP, systolic blood pressure; DBP, diastolic blood pressure; cMetS, continuous values of metabolic syndrome risk scores. 
application compliance did not affect changes in body weight (data not shown).

\section{DISCUSSION}

In this study, we aimed to evaluate the effectiveness of self-monitored mobile applications in weight management of patients with T2DM. We found that short-term mobile application use for lifestyle modification in patients with T2DM significantly reduces WC but not weight. Additionally, more evident WC reduction was observed in patients with good compliance, emphasizing the importance of adherence to digital therapeutics.

A previous study reported exercise-induced WC reduction without body weight changes ${ }^{21}$ in which participants showed a significant WC reduction without weight loss after exercising for 14 weeks. Additionally, they found that the WC reduction (up to $3 \mathrm{~cm}$ ) achieved by exercise was comparable with that of a dietary weight loss group wherein a up to $6 \%$ body weight reduction was achieved through caloric restriction alone. Similarly, regular exercise without weight loss resulted in substantial WC reduction in patients with T2DM. ${ }^{22}$ Mechanistically, exercise activates lipolysis in abdominal subcutaneous adipose tissue, resulting in whole-body fatty acid oxidation. ${ }^{23}$

Traditionally, BMI has been the most widely used marker of obesity. However, BMI cannot differentiate between abdominal and general obesity. Abdominal obesity has been shown to be strongly associated with cardiovascular outcomes. ${ }^{24} \mathrm{WC}$ is a marker of abdominal obesity, and previous studies have shown a stronger association of cardiovascular risk with WC than with BMI. ${ }^{25,26}$ Consistently, WC reduction exhibited cardiometabolic benefits. ${ }^{25-28}$ From these results, the International Atherosclerosis Society and International Chair on Cardiometabolic Risk Working Group suggested the utility of WC as a treatment goal and reiterated the importance of its routine measurement in addition to $\mathrm{BMI}{ }^{29}$ Thus, the WC reduction observed in our study is clinically relevant despite the lack of body weight reduction.

Technological advances have prompted researchers to investigate the effects of mobile applications on weight management; most have shown beneficial effects. ${ }^{30}$ Weight reduction enhances glucose homeostasis; therefore, trials involving patients with T2DM merit further investigation. However, there is a lack of studies involving weight management of T2DM patients using mobile applications. Recently, Cai et al. ${ }^{31}$ conducted a meta-analysis of randomized controlled trials examining the use of a mobile application in patients with T2DM. Contrary to our study, they found a modest but significant weight loss in patients with T2DM who used mobile applications; this finding was driven mainly by the studies of Orsama et al. ${ }^{32}$ and Wayne et al..$^{33}$ The latter performed a program comprised of approximately 40 minutes per week of health coach interventions provided for both control and intervention groups. On the other hand, Orsama et al. ${ }^{32}$ only included patients who voluntarily participated in the study; thus, participants were likely highly motivated. In addition, both studies conducted $\geq 6$ months of lifestyle intervention. Thus, the lack of effect of mobile applications on body weight in our study might be due to differences in study population or interventional methods. ${ }^{32,33}$ Further studies are needed to investigate the optimal approaches and the T2DM patient population that would most benefit from mobile applications.

A positive association was found between obesity outcomes and lifestyle modification program compliance. ${ }^{34}$ In our study, we also found that patients who exhibited good compliance to the application showed significantly greater WC reduction than those with poor compliance. A previous meta-analysis examining the factors promoting compliance revealed that a supervised attendance program was the most important factor, followed by social support. ${ }^{35}$ Supervised attendance is defined as monitoring of participants' attendance by a researcher. However, it is labor-intensive to monitor continually patient attendance in clinical practice. Recent studies have shown the promising utility of social media tools in enhancement of adherence to various clinical entities. ${ }^{36-38}$ Thus, the combination of mobile applications and social media tools can be helpful for continued lifestyle modification through induction of voluntary participation.

There are several limitations to this study. First, the small sample size might have insufficient power to determine treatment effects. Second, the intervention duration was short. Thus, changes in certain clinical endpoints were not addressed effectively. For example, $\mathrm{HbAlc}$ level represents the average glucose level over the previous 3 months ${ }^{39}$ and might not have reflected accurately acute changes in glucose level due to the short duration of our study. Third, the low effect size raises the possibility of measurement errors instead 
of clinically relevant changes in WC. However, each participant's WC was examined by the same examiner at both visits using a uniform measurement protocol to minimize measurement error. In addition, the greater WC reduction in patients with good compliance further supports the reliability of WC measurements in our study. Last, the single-center nature of the study limits its generalizability.

Intensive glycemic control is known to mitigate the development of microvascular complications. ${ }^{40}$ Future research should investigate the reduction in diabetic complications through long-term lifestyle modification with digital therapeutics. Additionally, studies focusing on the effect of digital applications in diabetes prevention or delay should be conducted since early intervention is essential in chronic diseases.

In summary, the results of this study suggest that lifestyle modification using mobile applications effectively reduces WC, especially in those with good adherence to the application. Given the strong association between WC and cardiometabolic disease risk, ${ }^{25,26}$ our results provide encouraging evidence supporting the use of digital therapeutics.

\section{CONFLICTS OF INTEREST}

The authors declare no conflict of interest.

\section{ACKNOWLEDGMENTS}

This work is supported by a Korea Agency for Infrastructure Technology Advancement (KAIA) grant funded by the Ministry of Land, Infrastructure, and Transport (Grant no. 21RERP-B09009408).

This work was supported by the Dongguk University Research Fund of S-2018-G0001-00042.

\section{AUTHOR CONTRIBUTIONS}

Study concept and design: SEL and SWO; acquisition of data: SEL, SKP, and YSP; analysis and interpretation of data: SEL and SKP; drafting of the manuscript: SEL, KAK, and HSC; critical revision of the manuscript: KAK, HSC, and SWO; statistical analy- sis: SEL and SKP; funding procurement: SWO; administrative, technical, or material support: SKP and YSP; and study supervision: SWO.

\section{SUPPLEMENTARY MATERIALS}

Supplementary materials can be found via https://doi.org/10. 7570/jomes21047.

\section{REFERENCES}

1. Khan MA, Hashim MJ, King JK, Govender RD, Mustafa H, Al Kaabi J. Epidemiology of type 2 diabetes: global burden of disease and forecasted trends. J Epidemiol Glob Health 2020; 10:107-11.

2. Cho NH, Shaw JE, Karuranga S, Huang Y, da Rocha Fernandes JD, Ohlrogge AW, et al. IDF diabetes atlas: global estimates of diabetes prevalence for 2017 and projections for 2045. Diabetes Res Clin Pract 2018;138:271-81.

3. Li S, Wang J, Zhang B, Li X, Liu Y. Diabetes mellitus and causespecific mortality: a population-based study. Diabetes Metab J 2019;43:319-41.

4. Papatheodorou K, Banach M, Edmonds M, Papanas N, Papazoglou D. Complications of diabetes. J Diabetes Res 2015; 2015:189525.

5. Bailey CJ, Day C. The future of new drugs for diabetes management. Diabetes Res Clin Pract 2019;155:107785.

6. Ling W, Huang Y, Huang YM, Fan RR, Sui Y, Zhao HL. Global trend of diabetes mortality attributed to vascular complications, 2000-2016. Cardiovasc Diabetol 2020;19:182.

7. Knowler WC, Barrett-Connor E, Fowler SE, Hamman RF, Lachin JM, Walker EA, et al. Reduction in the incidence of type 2 diabetes with lifestyle intervention or metformin. $\mathrm{N}$ Engl J Med 2002;346:393-403.

8. Feldstein AC, Nichols GA, Smith DH, Stevens VJ, Bachman K, Rosales AG, et al. Weight change in diabetes and glycemic and blood pressure control. Diabetes Care 2008;31:1960-5.

9. Diabetes Prevention Program Research Group, Knowler WC, Fowler SE, Hamman RF, Christophi CA, Hoffman HJ, et al. 10-Year follow-up of diabetes incidence and weight loss in the 
Diabetes Prevention Program Outcomes Study. Lancet 2009; 374:1677-86.

10. Palanica A, Docktor MJ, Lieberman M, Fossat Y. The need for artificial intelligence in digital therapeutics. Digit Biomark 2020;4:21-5.

11. Kvedar JC, Fogel AL, Elenko E, Zohar D. Digital medicine's march on chronic disease. Nat Biotechnol 2016;34:239-46.

12. Lin PH, Grambow S, Intille S, Gallis JA, Lazenka T, Bosworth $\mathrm{H}$, et al. The association between engagement and weight loss through personal coaching and cell phone interventions in young adults: randomized controlled trial. JMIR Mhealth Uhealth 2018;6:e10471.

13. Allen JK, Stephens J, Dennison Himmelfarb CR, Stewart KJ, Hauck S. Randomized controlled pilot study testing use of smartphone technology for obesity treatment. J Obes 2013; 2013:151597.

14. Korean Diabetes Association Education Committee. The guide for diabetes education. 3rd ed. Seoul: Gold' Planning and Development; 2013.

15. Hills AP, Mokhtar N, Byrne NM. Assessment of physical activity and energy expenditure: an overview of objective measures. Front Nutr 2014;1:5.

16. Cramer JA. A systematic review of adherence with medications for diabetes. Diabetes Care 2004;27:1218-24.

17. Obesity: preventing and managing the global epidemic. Report of a WHO consultation. World Health Organ Tech Rep Ser 2000;894:i-xii, 1-253.

18. Jeong SH, Lee NY, Kim SH, Chung IW, Youn T, Kang UG, et al. Long-term evolution of metabolic status in patients with schizophrenia stably maintained on second-generation antipsychotics. Psychiatry Investig 2018;15:628-37.

19. Grundy SM, Cleeman JI, Daniels SR, Donato KA, Eckel RH, Franklin BA, et al. Diagnosis and management of the metabolic syndrome: an American Heart Association/National Heart, Lung, and Blood Institute Scientific Statement. Circulation 2005;112:2735-52.

20. Alberti KG, Zimmet P, Shaw J; IDF Epidemiology Task Force Consensus Group. The metabolic syndrome: a new worldwide definition. Lancet 2005;366:1059-62.

21. Ross R, Janssen I, Dawson J, Kungl AM, Kuk JL, Wong SL, et al. Exercise-induced reduction in obesity and insulin resistance in women: a randomized controlled trial. Obes Res 2004; 12:789-98.

22. Dekker MJ, Lee S, Hudson R, Kilpatrick K, Graham TE, Ross $\mathrm{R}$, et al. An exercise intervention without weight loss decreases circulating interleukin- 6 in lean and obese men with and without type 2 diabetes mellitus. Metabolism 2007;56:332-8.

23. Laurens C, de Glisezinski I, Larrouy D, Harant I, Moro C. Influence of acute and chronic exercise on abdominal fat lipolysis: an update. Front Physiol 2020;11:575363.

24. Ritchie SA, Connell JM. The link between abdominal obesity, metabolic syndrome and cardiovascular disease. Nutr Metab Cardiovasc Dis 2007;17:319-26.

25. Zhu S, Wang Z, Heshka S, Heo M, Faith MS, Heymsfield SB. Waist circumference and obesity-associated risk factors among whites in the third National Health and Nutrition Examination Survey: clinical action thresholds. Am J Clin Nutr 2002;76: 743-9.

26. Janssen I, Katzmarzyk PT, Ross R. Waist circumference and not body mass index explains obesity-related health risk. Am J Clin Nutr 2004;79:379-84.

27. Han TS, Richmond P, Avenell A, Lean ME. Waist circumference reduction and cardiovascular benefits during weight loss in women. Int J Obes Relat Metab Disord 1997;21:127-34.

28. Fanghänel G, Sánchez-Reyes L, Félix-García L, Violante-Ortiz $\mathrm{R}$, Campos-Franco E, Alcocer LA. Impact of waist circumference reduction on cardiovascular risk in treated obese subjects. Cir Cir 2011;79:175-81.

29. Ross R, Neeland IJ, Yamashita S, Shai I, Seidell J, Magni P, et al. Waist circumference as a vital sign in clinical practice: a Consensus Statement from the IAS and ICCR Working Group on Visceral Obesity. Nat Rev Endocrinol 2020;16:177-89.

30. Ghelani DP, Moran LJ, Johnson C, Mousa A, Naderpoor N. Mobile apps for weight management: a review of the latest evidence to inform practice. Front Endocrinol (Lausanne) 2020;11:412.

31. Cai X, Qiu S, Luo D, Wang L, Lu Y, Li M. Mobile application interventions and weight loss in type 2 diabetes: a meta-analysis. Obesity (Silver Spring) 2020;28:502-9.

32. Orsama AL, Lähteenmäki J, Harno K, Kulju M, Wintergerst E, 
Schachner $\mathrm{H}$, et al. Active assistance technology reduces glycosylated hemoglobin and weight in individuals with type 2 diabetes: results of a theory-based randomized trial. Diabetes Technol Ther 2013;15:662-9.

33. Wayne N, Perez DF, Kaplan DM, Ritvo P. Health coaching reduces $\mathrm{HbAlc}$ in type 2 diabetic patients from a lower-socioeconomic status community: a randomized controlled trial. J Med Internet Res 2015;17:e224.

34. Leung AW, Chan RS, Sea MM, Woo J. An overview of factors associated with adherence to lifestyle modification programs for weight management in adults. Int J Environ Res Public Health 2017;14:922.

35. Lemstra M, Bird Y, Nwankwo C, Rogers M, Moraros J. Weight loss intervention adherence and factors promoting adherence: a meta-analysis. Patient Prefer Adherence 2016;10:1547-59.

36. Klassen KM, Douglass CH, Brennan L, Truby H, Lim MS. Social media use for nutrition outcomes in young adults: a mixed-methods systematic review. Int J Behav Nutr Phys Act 2018; $15: 70$.

37. Prochaska JJ, Coughlin SS, Lyons EJ. Social media and mobile technology for cancer prevention and treatment. Am Soc Clin Oncol Educ Book 2017;37:128-37.

38. Bychkov D, Young S. Social media as a tool to monitor adherence to HIV antiretroviral therapy. J Clin Transl Res 2018; 3(Suppl 3):407-10.

39. International Expert Committee. International Expert Committee report on the role of the $\mathrm{A} 1 \mathrm{C}$ assay in the diagnosis of diabetes. Diabetes Care 2009;32:1327-34.

40. UK Prospective Diabetes Study (UKPDS) Group. Intensive blood-glucose control with sulphonylureas or insulin compared with conventional treatment and risk of complications in patients with type 2 diabetes (UKPDS 33). Lancet 1998; 352:837-53. 